\title{
Conservative treatment reduced pain and was as effective as sutures in hand lacerations $<2 \mathrm{~cm}$
}

Quinn J, Cummings S, Callaham M, et al. Suturing versus conservative management of lacerations of the hand: randomised
controlled trial. BMJ 2002;325:299-300.

\section{QUESTION: In patients with hand lacerations, is conservative treatment as effective as suturing?}

\section{Design}

Randomised (allocation concealed*), blinded (primary outcome only), ${ }^{*}$ controlled trial with 3 months of follow up.

\section{Setting}

Emergency department of a university hospital in San Franciso, California, USA.

\section{Patients}

95 patients (mean age 39 y, 54\% men) who had lacerations distal to the volar wrist crease. Exclusion criteria were lacerations $>2 \mathrm{~cm}$ long; presentation $>8$ hours after the injury; inability to attain haemostasis after 15 minutes; neurovascular, tendon, or bone injury; lacerations that were of the nail bed, puncture wounds, or secondary to a bite from any source; complications from diabetes; use of anticoagulants; or prolonged use of steroids. Follow up at 3 months was $85 \%$.

\section{Intervention}

Patients were allocated to conservative treatment $(n=48)$ or suturing $(n=47)$. Patients in the conservative treatment group had the area of laceration irrigated with tap water, and a polymixin $\mathrm{B}$ antibiotic ointment (containing bacitracin) and a gauze dressing were applied to last 48 hours. Patients in the suture group had the area of laceration anaesthetised and cleansed. The skin was closed with monofilament suture (US pharmacopoeia sizes $4-0$ or 5-0). The same ointment and dressing were applied to last 24-48 hours.

\section{Main outcome measures}

The primary outcome measure was cosmetic appearance (rated by doctors blind to treatment groups on a 0-100 mm [best scar] visual analogue scale [VAS]). Other outcome measures were pain of treatment rated by patients (0-100 $\mathrm{mm}$ [worst pain possible] VAS) and time to return to normal daily activities. An optimal wound score scale was also used, but $<80 \%$ of patients were evaluated for this outcome.

\section{Main results}

The treatment groups did not differ for cosmetic appearance (rated by doctors or patients) or time to return to normal daily activities (table). Patients in the conservative treatment group reported less pain than those in the suture group (table).

Conservative treatment $v$ sutures for hand lacerations at 3 months

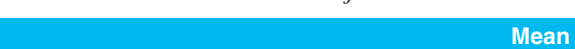

Source of funding: US National Institutes of Health.

For correspondence: Dr J Quinn, University of California at San Francisco, San Francisco, CA, USA quinnj@medicine.ucsf.edu

tRated on a visual analogue scale, 0-100 mm (best score).

Not statistically significant.

\section{Conclusion}

In patients with lacerations of the hand, conservative treatment was as effective as suturing and was less painful.

*See glossary.

\section{COMMENTARY}

The excellent study by Quinn $e t$ al answers an important question: should some lacerations be treated conservatively in the emergency department? It is reassuring to the practising emergency physician that the investigators found no difference between groups in cosmetic results. Pain during the procedure was another outcome measure. In California emergency departments, pain has become the fifth vital sign, and anything that improves patient comfort during treatment is important. In addition to reducing pain, conservative treatment probably saves time, which is critical in overcrowded emergency departments.

The small sample size resulted in not enough power to evaluate complications such as wound infections, which are relatively rare. At 3 months, physicians who rated the cosmetic results, the main outcome measure, were adequately blinded to treatment groups.

Three letters in the November 2002 issue of $B M J$ warned that hand lacerations should be explored and examined carefully before conservative management could be considered. $^{1-3}$ These potential complications were addressed in the exclusion criteria of this study. Physicians should be certain that a simple laceration is indeed simple, and normal precautions such as ruling out a tendon injury, foreign body, or deep wound should be incorporated in initial treatment Further review of the literature shows few articles that address conservative management of lacerations, making this study an important contribution to the wound management literature.

It would be helpful to emergency physicians if future studies of conservative management of lacerations addressed other locations (ie, face, torso, and scalp). I would also want to know whether the number of infections differ, even if it is a rare complication. Infection rate can only be addressed in a very large study but should be considered in the future.

Amy A Ernst, MD University of California, Davis Sacramento, California, USA

1 Irvine AJ. Suturing v conservative management of hand lacerations. Incisions are not lacerations [letter]. BMJ 2002; 325:1113.

2 Dunn R, Watson S. Suturing v conservative management of hand lacerations. Hand lacerations should be explored before conservative treatment [letter]. BMJ 2002;325:1113.

3 De Souza BA, Shibu M, Moir G, et al. Suturing v conservative management of hand lacerations. All lacerations need to be management of hand lacerations. All lacerations ne

\begin{tabular}{llll} 
Cosmetic appearance rated by doctors $\dagger$ & 80 & 83 & $3(-1$ to 8$) \ddagger$ \\
\hline Cosmetic appearance rated by patients $\dagger$ & 82 & 83 & $1(-7$ to 9$) \ddagger$ \\
\hline Time to resume normal activities (days) & 3.4 & 3.4 & $0(-1.4$ to 1.3$) \ddagger$ \\
\hline Pain during treatment§ & 13 & 31 & 18 (12 to 24$)$
\end{tabular}

§Rated on a visual analogue scale, 0-100 mm (worst score). 